\title{
Stroke Epidemiology in Douala: Three Years Prospective Study in a Teaching Hospital in Cameroon
}

\author{
Yacouba N. Mapoure 1,2, C. Kuate3, Clet B. Tchaleu2,4, Hugo B. Mbatchou Ngahane1, \\ Gérard N. Mounjouopou1, Hamadou Ba ${ }^{3}$, Salomon Mbahe ${ }^{2}$, Julius Y. Fonsah" ${ }^{5}$, \\ Gérard Beyiha6, Henry N. Luma ${ }^{2,3}$, Albert S. Mouelle², Philomène K. Ndouongo ${ }^{7}$, \\ Alfred K. Njamnshi ${ }^{3}$ \\ ${ }^{1}$ Department of Clinical Sciences, University of Douala, Douala, Cameroon \\ ${ }^{2}$ Department of Internal Medicine, Douala General Hospital, Douala, Cameroon \\ ${ }^{3}$ Department of Internal Medicine, University of Yaoundé I, Douala, Cameroon \\ ${ }^{4}$ Department of Clinical Sciences, Université des Montagnes, Douala, Cameroon \\ ${ }^{5}$ Department of Neurology, Yaoundé Central Hospital, Yaoundé, Cameroon \\ ${ }^{6}$ Department of Surgery, University of Douala, Douala, Cameroon \\ ${ }^{7}$ Department of Neurology, University of Health Sciences, Libreville, Gabon \\ Email: mapoureyacouba@gmail.com
}

Received 25 August 2014; revised 26 September 2014; accepted 3 October 2014

Copyright (C) 2014 by authors and Scientific Research Publishing Inc.

This work is licensed under the Creative Commons Attribution International License (CC BY).

http://creativecommons.org/licenses/by/4.0/

c) (i) Open Access

\section{Abstract}

Background and Objectives: Cerebro-vascular accident or stroke constitutes a major challenge in sub-Saharan Africa. In Cameroon, basic epidemiologic data are not routinely available. Aims: The aim of this study was to determine the type, the associated risk factors, time to admission, the clinical presentation and the case fatality of stroke at the Douala General Hospital (DGH) in Cameroon. Methods: A cross-sectional study was performed from January 1, 2010 to December 31, 2012 at the neurology and intensive care units of the DGH. All patients above 15 years of age with a diagnosis of established stroke were enrolled. For each patient, socio-demographic, clinical and paraclinical data were recorded as well as the duration of hospitalization and the case fatality. Results: In all, 325 patients were enrolled with males constituting $68.1 \%$ and general mean age of $58.66 \pm 13.6$ years. The mean initial consultation delay was $47.36 \pm 18.48$ hours. The majors cerebro-vascular risk factors were hypertension $(\mathbf{8 1 . 1 5 \%})$, chronic alcohol consumption $(\mathbf{2 8 . 3 \% )}$, diabetes mellitus $(20.61 \%)$, obesity $(18.15 \%)$, cigarette smoking $(16 \%)$, dyslipidemia $(8.9 \%)$ and atrial fibrillation $(3.07 \%)$. Ischemic stroke accounted for $52 \%$ of cases while $48 \%$ were hemorrhagic. The mean duration of hospitalization was $8.58 \pm 6.35$ days with a case fatality rate of $\mathbf{2 6 . 8 \%}$. Septic conditions appeared to be the leading cause of death accounting for $35.6 \%$ of cases.

How to cite this paper: Mapoure, Y.N., Kuate, C., Tchaleu, C.B., Mbatchou Ngahane, H.B., Mounjouopou, G.N., Ba, H., Mbahe, S., Fonsah, J.Y., Beyiha, G., Luma, H.N., Mouelle, A.S., Ndouongo, P.K. and Njamnshi, A.K. (2014) Stroke Epidemiology in Douala: Three Years Prospective Study in a Teaching Hospital in Cameroon. World Journal of Neuroscience, 4, 406414. http://dx.doi.org/10.4236/wjns.2014.45044 
Conclusion: Stroke in the DGH is associated with a high case fatality rate and hypertension remains the number one risk factor. There is a clear and urgent need for public health authorities to reinforce measures for the control of modifiable stroke risk factors.

\section{Keywords}

\section{Stroke, Epidemiology, Risk Factors, Case Fatality, Douala, Cameroon}

\section{Introduction}

Stroke is the second leading cause of death worldwide [1]. Over the last 20 years, modifications of the disease epidemiology have been observed in Sub-Saharan Africa with emergence of non-communicable chronic diseases like hypertension, diabetes mellitus, dyslipidemia and the obesity [2] [3]. On the other hand, substantial modifications of lifestyle are also observed with increasing sedentary tendencies, alcohol consumption and tobacco smoking. All these conditions are prone to increase the incidence of stroke in this part of the world. Data on stroke in Cameroon are scarce and are generally related to specific conditions [4]-[10].

\section{Objective}

The objective of this study was to determine the type, the associated risk factors, time to admission, the clinical presentation and the case fatality of stroke at a reference hospital in Cameroon: the Douala General Hospital (DGH).

\section{Materials and Methods}

\subsection{Study Setting}

Douala, the economic capital of Cameroon has a population of 3 million inhabitants, an equatorial climate and is situated in the Gulf of Guinea. The DGH is a state-owned teaching hospital with 320 beds for the following departments: paediatrics, surgery, gynaecology and obstetrics, cobaltotherapy, nephrology and haemodialysis, intensive care, emergency, and internal medicine. The imaging department operates an 8-barettes CT scan allowing for 24 hours daily service. Magnetic resonance imaging is available in Douala only in the private sector (the cost of a brain MRI was $381.38 €$ at time of study). Stroke patients were hospitalized in the neurology unit (NU) of the internal medicine department and those with severe conditions at admission were hospitalized in the intensive care unit (ICU).

\subsection{Study Design and Patient Management}

A prospective cross-sectional study was performed from January $1^{\text {st }} 2010$ to December $31^{\text {st }} 2012$. All consenting patients more than 15 years of age with clinical diagnosis of stroke and CT scan confirmation were enrolled. Patients with severe clinical state (Glasgow Coma Scale $<8 / 15$ or septic shock) were admitted directly into ICU while other cases were hospitalized in the NU. For each patient, socio-demographic, past medical history and clinical data were recorded. Initial consultation delay for initial consultation was also accessed as difference in time of onset of symptoms to time of consultation. The definitions of vascular risk factors are found in Table 1. Upon admission, vital signs included blood pressure, pulse, respiratory rate, oxygen saturation, temperature, capillary glycaemia and dipstick urine analysis were recorded. Neurological assessment was done by a neurologist or intensive care specialist or both. Interpretation of CT scans was done by both radiologists and neurologists. Electro-cardiography was systematically done for patient with ischemic strokes and for hypertensive patients with hemorrhagic strokes. For patients with ischemic stroke, transthoracic and supra-aortic Doppler ultrasound studies were done; except for critically ill patients. Blood samples were collected for standard assessments including: a full blood count with platelet counts, urea and creatinine, electrolytes, fasting glucose, lipid profile, prothrombin time, cephaline-kaoline time, uric acid, C-reactive protein, erythrocyte sedimentation rate and HIV serology. Other tests were prescribed if required by the patients' conditions: chest X-ray, urine culture, haemoculture, thick blood film to check for Plasmodium falciparum. Patient follow-up was done daily for clini- 
Table 1. Definition of vascular risk factors.

\begin{tabular}{|c|c|}
\hline Vascular Risk Factors & Definition \\
\hline Hypertension & $\begin{array}{l}\text {-Patient with medical history of hypertension, treated or not. Or } \\
\text {-Patient with persistent high blood pressure }>140 / 90 \mathrm{mmHg} \text { after stroke }\end{array}$ \\
\hline Diabetes Mellitus & $\begin{array}{l}\text {-Patient with medical history of diabetes, treated or not. Or } \\
\text {-Random serum glucose }>\text { or }=2 \mathrm{~g} / \mathrm{l} \text {. Or venous fasting glucose test }>1.26 \mathrm{~g} / \mathrm{l}\end{array}$ \\
\hline Dyslipidemia & $\begin{array}{l}\text { One of these conditions } \\
\text {-Patient with medical history of dyslipidemia or } \\
\text {-Total cholesterol }>2 \mathrm{~g} / \mathrm{l} \text { or } \\
\text {-Low density lipoprotein }>1 \mathrm{~g} / \mathrm{l} \text { or } \\
\text {-High density lipoprotein }<0.40 \mathrm{~g} / \mathrm{l} \text { or }\end{array}$ \\
\hline Sleep Apnoea Disease & $\begin{array}{l}\text { Suspected in patient with } 3 \text { of these conditions: } \\
\text {-Snoring when sleeping } \\
\text {-Apnea during sleeping } \\
\text {-Excessive diurnal sleepiness } \\
\text {-Can be associated with obesity }\end{array}$ \\
\hline Alcohol Consumption & Daily alcohol intake $>40 \mathrm{~g} / \mathrm{l}$ \\
\hline Obesity & $\begin{array}{l}2 \text { methods were used } \\
\text {-the body mass index > 30: obesity } \\
\text {-and when it's impossible to have the BMI, we used the abdominal circumference: } \\
>102 \mathrm{~cm} \text { in male and }>88 \mathrm{~cm} \text { in female }\end{array}$ \\
\hline
\end{tabular}

cal evaluation and any complications were recorded. In case of death, a staff meeting was held to ascertain the cause of death. Oxygen was administrated if ambient oxygen saturation was less than $94 \%$. Paracetamol was administered to patients who developed a fever (body temperature superior to $37.5^{\circ} \mathrm{C}$ ) at a dose of $1 \mathrm{~g}$ six-hourly. Prevention of deep venous thrombosis and stress ulcers was done using prophylactic dose of enoxaparine (40 $\mathrm{mg}$ ) and omeprazole $(20 \mathrm{mg}$ ) respectively. An insulin protocol was set up when capillary glycaemia was above $1.4 \mathrm{~g} / \mathrm{l}$. Concerning blood pressure management, nicardipine was given intraveniously with an electric syringe in case of high blood pressure with a target of 140 to $160 \mathrm{mmHg}$ for systolic blood pressure in hemorrhagic stroke. In ischemic stroke, early elevated blood pressure was not tempered with excepted when it was above $220 \mathrm{mmHg}$. Aspirin (100 - $250 \mathrm{mg}$ per day) was given in ischemic stroke while a curative dose of low molecular weight heparin was used in case of atrial fibrillation with CHADS $>3$, presence of intraluminal thrombus in a cerebral artery or presence of blood clot in the heart. Antibiotics and arthemeter were administered in case of bacterial infection and malaria respectively. Thrombolysis treatment is not yet practiced in Cameroon.

\subsection{Statistical Analysis}

We used the SPSS software version 20 to analyse data. Khi-square and Fisher tests were used to compare qualitative variables while the Student's T test was performed for quantitative variables. P values $<0.05$ were considered statistically significant.

\subsection{Ethical Issues}

We obtained clearance from the National Ethic Committee. The objective of the study and other relevant information was explained to each patient or their relative and their (oral or written) consent was obtained.

\section{Results}

A total of 325 patients were enrolled with 258 (79.39\%) from the NU and 67 (20.61\%) from the ICU. There were 201 males representing $68.1 \%$ of cases with a M/F sex ratio of 1.62 . Figure 1 shows the distribution of patients according to age and sex while Table 2 presents the characteristics of the study population. The mean age of male was $58.66 \pm 13.06$ years and the mean age of female at 61.56 years $(P=0.002)$. Some 127 patients (39.1\%) were admitted directly from their homes while 198 (61.1\%) were referred from public health care centres (109 cases) and private clinic (89 cases).

Table 3 gives the known cerebro-vascular risk factors (CVRF) before stroke considering the nature of stroke. 
Table 2. Sociodemographic characteristics of patients.

\begin{tabular}{|c|c|c|}
\hline & Number (n) & Percentage \\
\hline \multicolumn{3}{|l|}{ Instruction Level } \\
\hline Illiterate & 35 & 7.7 \\
\hline Primary & 73 & 16.3 \\
\hline Secondary & 99 & 23.7 \\
\hline University & 118 & 28.6 \\
\hline Total & 325 & 100.0 \\
\hline \multicolumn{3}{|l|}{ Profession } \\
\hline No & 156 & 48.0 \\
\hline Yes & 169 & 52.0 \\
\hline Total & 325 & 100.0 \\
\hline \multicolumn{3}{|l|}{ Care's Payment } \\
\hline Insurance & 53 & 16.3 \\
\hline Individual & 11 & 3.4 \\
\hline Individual and Family & 29 & 8.9 \\
\hline Family Alone & 232 & 71.4 \\
\hline Total & 325 & 100.0 \\
\hline \multicolumn{3}{|l|}{ Patient's Residence } \\
\hline Douala & 207 & 63.7 \\
\hline Littoral & 42 & 12.9 \\
\hline Other Region & 71 & 21.8 \\
\hline Abroad & 5 & 1.5 \\
\hline Total & 325 & 100.0 \\
\hline
\end{tabular}

Table 3. Known cerebro-vascular risk factors in patients.

\begin{tabular}{ccccc}
\hline Stroke Risk Factors & Ischaemic N (\%) $^{*}$ & Haemorrhagic N (\%) $^{* *}$ & Total N (\%) $^{* * *}$ & P $^{*}$ \\
\hline High Blood Pressure & $127(74.71 \%)$ & $100(64.52 \%)$ & $227(69.84 \%)$ & 0.46 \\
Alcohol & $50(29.42 \%)$ & $42(27.10 \%)$ & $92(28.30 \%)$ & 0.64 \\
Diabetes & $49(28.83 \%)$ & $18(11.62 \%)$ & $67(20.61 \%)$ & 0.00 \\
Overweigh/Obesity & $42(24.705)$ & $17(10.96 \%)$ & $59(18.15 \%)$ & 0.02 \\
Tobacco & $28(16.47 \%)$ & $24(15.49 \%)$ & $52(16 \%)$ & 0.80 \\
Past History of Stroke & $24(14.12 \%)$ & $14(9.04 \%)$ & $38(11.69 \%)$ & 0.15 \\
Dyslipidemia & $21(12.36 \%)$ & $08(5.17 \%)$ & $29(8.9 \%)$ & 0.02 \\
Other Emboligenic Cardiopathy & $21(12.36 \%)$ & $05(3.23 \%)$ & $26(8 \%)$ & 0.02 \\
Sleep Apnoea Syndrome & $06(3.53 \%)$ & $05(3.23 \%)$ & $11(3.38 \%)$ & 0.88 \\
Atrial Fibrillation & $09(5.30 \%)$ & $01(0.65 \%)$ & $10(3.07 \%)$ & 0.01 \\
HIV Seropositivity & $05(2.95 \%)$ & $05(3.23 \%)$ & $10(3.07 \%)$ & 0.56 \\
\hline
\end{tabular}

${ }^{*}=$ Percentage relative to ischemic stroke $(\mathrm{N}=170) ;{ }^{* *}=$ Percentage relative to hemorrhagic stroke $(\mathrm{N}=155) ;{ }^{* * *}=$ Percentage relative to the total study population $(\mathrm{N}=325) ; \mathrm{P}=0.05$ : Level of significance comparing ischaemic and haemorrhagic strokes. 


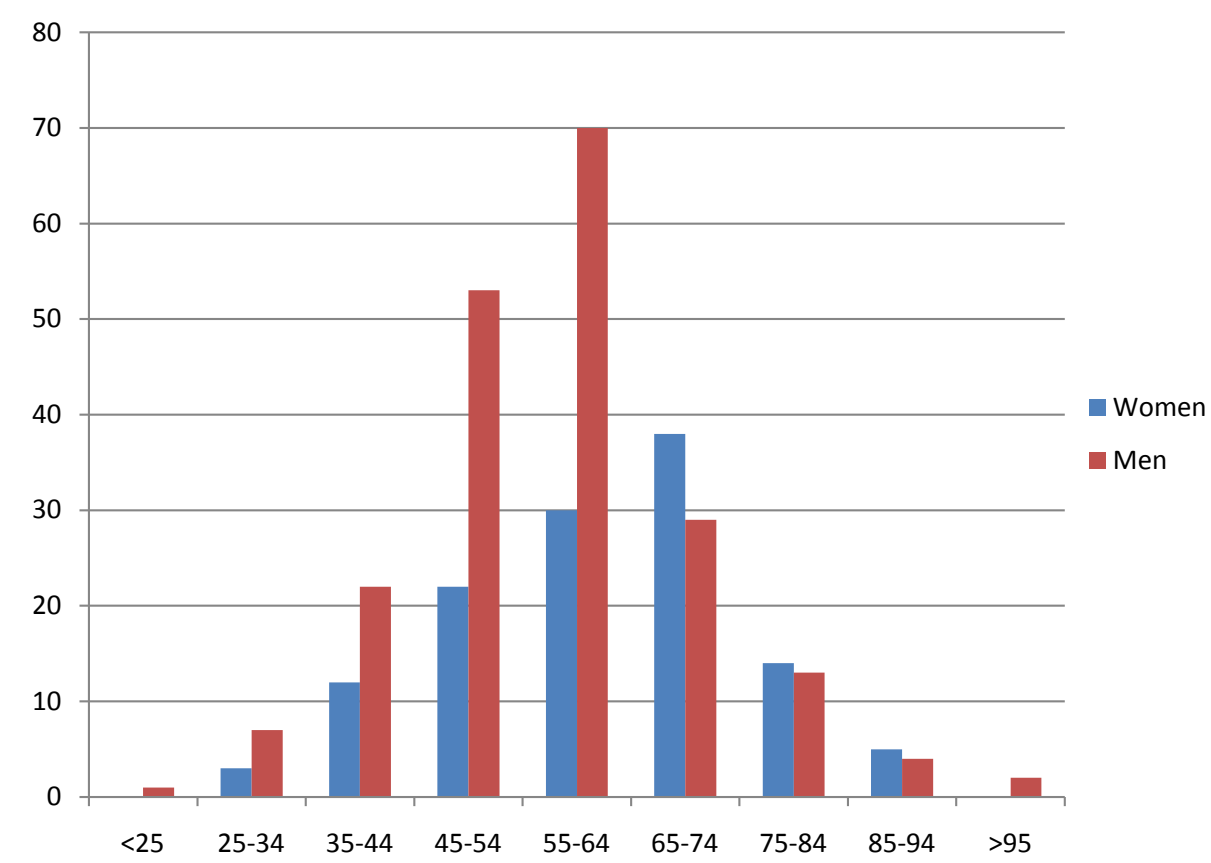

Figure 1. Distribution of patients according to age group and sex.

The prevalence of hypertension was $81.53 \%$ (265 cases out of which 38 cases were de novo new cases of high blood pressure). The situation was similar for diabetes mellitus and dyslipidemia where 10 and 16 new cases were diagnosed giving a prevalence of $23.69 \%$ and $14.15 \%$ respectively. Fourteen new cases of atrial fibrillation were diagnosed giving a prevalence of $13.53 \%$ during ischemic stroke.

The mean delay from the onset of symptoms suggestive of stroke and the initial consultation was $47.36 \pm$ 18.48 hours (1 to 441.75 hours). The mean delay for consultation at the DGH was $96.37 \pm 64.99$ hours (range: 1 to 720 hours). Only 84 patients (25.84\%) consulted in the DGH before 4.5 hours from the beginning of symptoms.

Table 4 shows the clinical characteristics on admission. Up to 167 patients (51.3\%) had a capillary glycaemia above to $1.4 \mathrm{~g} / \mathrm{l}$ and the temperature was above or equal to $38.5^{\circ} \mathrm{C}$ for $29(8.9 \%)$ patients. The Glasgow coma score was inferior or equal to $8 / 15$ for $58(17.8 \%)$ patients. Urine analysis showed a suspicion of urinary tract infection based on the presence of both nitrite and leucocytes in 31 patients $(9.53 \%)$. Glucosuria, proteinuria and cetonuria were positive in respectively 85 (26.25\%), 34 (10.46\%) and 31 (9.53\%). Figure 2 shows the different types and subtypes of stroke. Ischemic and haemorrhagic strokes represented respectively $52 \%$ and $48 \%$ of cases. Strokes were associated with one or more comorbid conditions as shown on Table 5. The global (NU and ICU) mean duration of hospitalization was $8.56 \pm 6.35$ days. The case fatality rate was $26.8 \%$. Septic conditions appeared to be the leading cause of death in $35.6 \%$.

\section{Discussion}

Although stroke is the second cause of death and the first cause of acquired handicap worldwide, its incidence in the general population remains poorly studied in sub-Saharan Africa [11]. In Cameroon, some studies have been carried on patients in the intensive care units [7] [8], sickle cell children [4] [6] and on risk factors of stroke [5] [10]. The only study that employed modern imaging technique (CT or MRI) is that of Chiasseu and Mbahe [9] although it looked mainly at less severe stroke in a small sample and very little information was reported on stroke subtypes. The study we report in this paper included cases in the intensive care and neurology units allowing a better sample size to study epidemiological features of stroke.

The mean age of the patients was $58.66 \pm 13.06$ years and was higher in women than in men. Sagui et al. in Dakar, Senegal found a mean age of $61.9 \pm 12.4$ in 2008 in Dakar [12], a result similar to that of other developing countries [13] [14]. The mean age in the current study is 8 to 15 years lower than that observed in developed countries [15] [16]. Situation is same with life expectancy between developing and developed countries. But we 


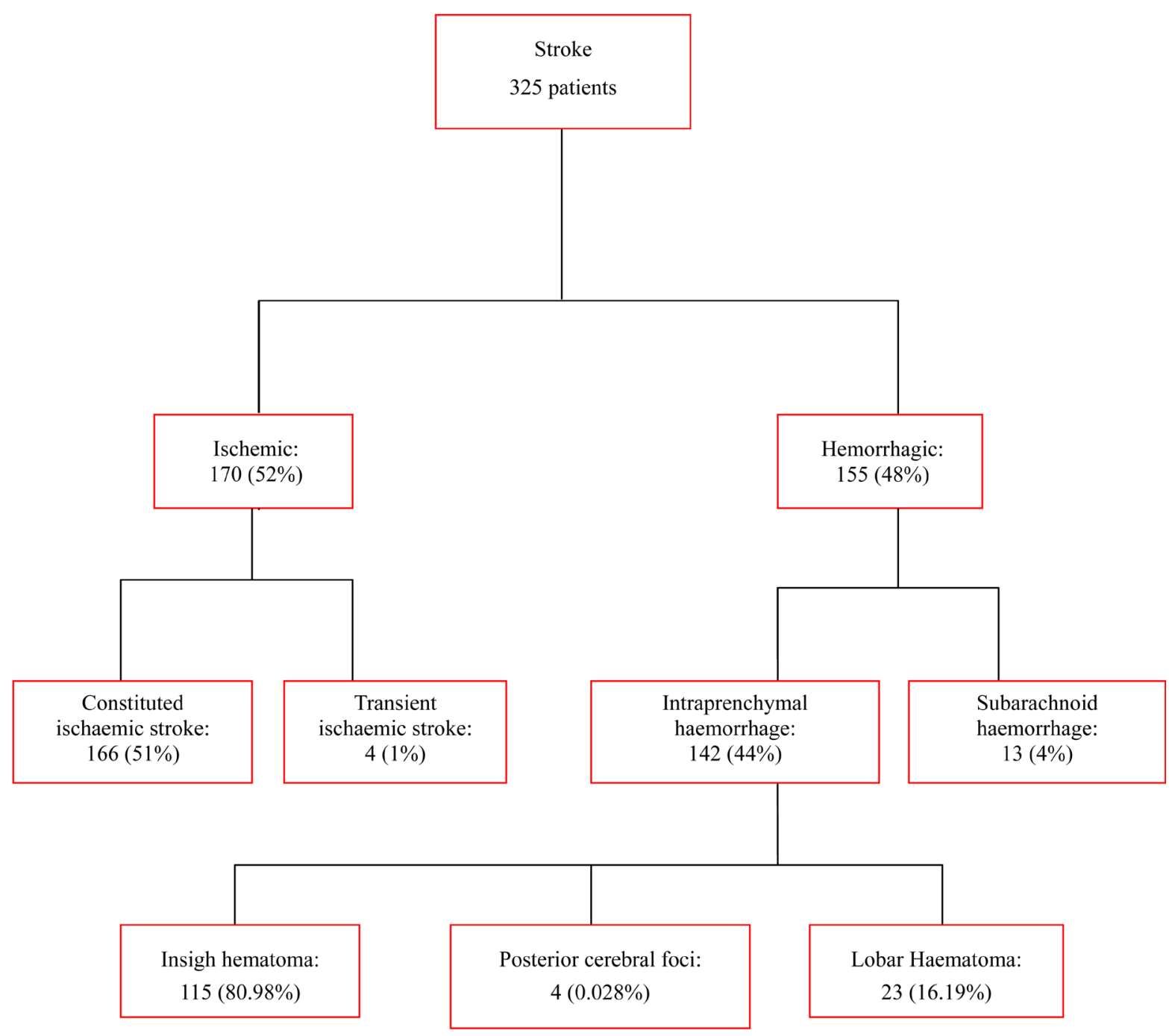

Figure 2. Types and subtypes of stroke.

Table 4. Clinical characteristics of patients at entrance.

\begin{tabular}{ccccc}
\hline & Mean & Standard Deviation & Minimum & Maximum \\
\hline Systolic BP (mmHg) & 168.38 & 33.60 & 88 & 255 \\
Diastolique BP (mmHg) & 100.88 & 20.50 & 50 & 171 \\
Pulse Rate (/min) & 84.41 & 19.32 & 26 & 169 \\
Respiratory Rate (/min) & 23.75 & 9.24 & 12 & 99 \\
Temperature $\left({ }^{\circ} \mathrm{C}\right)$ & 37.29 & 0.76 & 35.8 & 40.30 \\
Capillary Glycaemia (g/l) & 1.47 & 0.77 & 0.23 & 5.99 \\
Glasgow Coma Score & 12.25 & 3.35 & 3 & 15 \\
\hline
\end{tabular}

$\mathrm{BP}=$ Blood pressure.

cannot give an exact explanation relative to this difference of age at stroke onset in the two situations, may be easily access to healthcare for CVRF screening. In Cameroon, patients generally seek medical care only when they have symptoms. 
Table 5. Associated cerebrovascular risk factors in stroke patient.

\begin{tabular}{ccc}
\hline Associated Condition & Number & Percentage (\%) \\
HBP & 166 & 51.1 \\
HBP/Diabetes & 56 & 17.2 \\
Atrial Fibrillation & 18 & 5.5 \\
HBP/Dyslipidaemia & 19 & 5.3 \\
HBP/Diabetes/Renal Failure & 8 & 2.5 \\
HBP/Dyslipidaemia/Diabetes & 6 & 1.8 \\
HBP/Atrial Fibrillation & 6 & 1.8 \\
Diabetes & 4 & 1.2 \\
HBP/Diabetes/Dyslipidaemia/Renal Failure & 2 & 0.6 \\
HBP/Dyslipidaemia/Renal Failure & 2 & 0.6 \\
Dyslipidaemia & 16 & 4.7 \\
Diabetes/Dyslipidaemia & 1 & 0.3 \\
\hline
\end{tabular}

HBP = High blood pressure.

There were more men in this study making up $68.1 \%$ of the cases. Apart from the study by Kouna et al. in Gabon [17], the masculin predominance of stroke is reported in other studies carried out in sub-Saharan Africa and elsewhere [12]-[14] [18]. This masculine predominance may be partly explained by the hormonal differences and lifestyle of men who tend to consume alcohol and tobacco more than women in our setting.

The majority of enrolled patients were living in Douala and its environs, while $21.8 \%$ were referred from other regions of Cameroon. The absence of basic stroke infrastructure, inadequacy and specialized personnel in other regions of the country apart Yaoundé and Douala can explain the referral of patients to the Douala General hospital which is better equipped to handle cerebrovascular diseases. There is need for population studies to access the incidence and risk factors of stroke in the country as this information will constitute the basis of a nation-wide stroke management and risk factors control programme.

Concerning the stroke risk factors known before the occurrence of stroke, $69.84 \%$ of the patients were hypertensive, and with newly diagnosed patients, this prevalence rose to $81.53 \%$. The prevalence hypertension in stroke victims appears to be lower in developed countries [15] [16] and is situated around 55\%. The review of Sagui [19] on stroke in sub Saharan Africa estimated the prevalence of hypertension between $32.3 \%$ and $68 \%$ among stroke victims. In Cameroon, there has been significant progression of the prevalence of hypertension both in rural and urban area [20]. At discharge from hospitalization, 23.69\% of the patients were confirmed with diabetes mellitus whereas only $20.61 \%$ of them were known to be diabetic before the onset of stroke. Amu et al. [21] screened $26.25 \%$ of diabetics among stroke victims in 2002 in Nigeria. Apetse et al. found $30.7 \%$ of diabetic patients in a sample of 307 patients in Togo in 2007 [22]. These results however differ from those of Touré et al. [23] who report a 9.2\% prevalence of diabetes in stroke patients in Senegal. Nigerian and Cameroonian population share several similarities in terms of biological and cultural characteristics. On the other hand, the low rate of diabetes in Senegalese may be due to their Sahelien style of life and the possible existence of environmental factors which may influence the risk of diabetes cannot be totally excluded. The prevalence rate of diabetes in stroke patients is similar to ours in Europe [15] but lower than 45\% reported in Saudi Arabia [14]. We found regular consumption of alcohol to be an important vascular risk factor in this study, present in $28.30 \%$ of cases. Kouna et al. had a similar result with $27.1 \%$ of cases in Gabon, a country located along the southern border of Cameroon. There is no strict control of alcohol consumption in Cameroon and there is a significant among of an indigenous production of alcohol that is consumed mainly by poor people. Many studies do not report this risk factor may be for religious reasons [12]-[14]. Tobacco consumption was present in $16 \%$ of the patients and especially in men, in our study. Napon et al. in Burkina Faso found similar results: $17.1 \%$ in a sample of 70 cases of stroke [24] while Kouna et al. [17] reported 9.5\% tobacco consumption in a sample of 105 pa- 
tients. These findings suggest the high level of tobacco consumption as a modifiable risk factor on which the sensitization of the population should be focused. Before stroke, $8.9 \%$ of the patients were known for dyslipidaemia and in the course of stroke, this prevalence rose to $13.83 \%$ in our sample. Apetse et al. in Togo in 2007 (22) reported a prevalence of $32.12 \%$ cases of dyslipidemia in a sample of 301 patients with stroke. Before the onset of ischemic stroke $5.3 \%$ of the patients had a past medical history of atrial fibrillation. Among the 24 cases of patients we received in atrial fibrillation, $23(13.53 \%)$ were recognised as being the cause of the ischaemic stroke. Amu et al. in Nigéria [21] screened 6.25\% cases of atrial fibrillation. Other studies did not mention their ECG results [9] [12] [17] [18]. In developed countries, the prevalence of atrial fibrillation in the course of constituted ischaemic stroke is estimated between $15 \%$ and $20 \%$ [15] [16].

In the current study, ischaemic stroke is slightly more frequent (52\%) than for haemorrhagic stroke (48\%). Similar results have been found by Komolafe et al. in Nigeria [18] with $51.1 \%$ ischaemic stroke. Kouna et al. in 2005 in Gabon [17] reported 61.9\% cases of ischaemic stroke in a population of patients hospitalized the neurology department. In Europe, 80\% of strokes are ischemic in nature [15]; similar to what obtains in Middle East [13] [14] [16]. Are there any existences of genetic or environmental factors which may explain this high prevalence of ischaemic stroke? Are there any biaises for example: are the haemorrhagic strokes so severe that the patients die in the communities (given the high prevalence of HBP) and are therefore not seen in the health facilities? Verbal autopsies could be helpful to attempt an answer to this question.

In-hospital mortality in this study was $26.8 \%$ for a mean duration of hospitalisation of $8.56 \pm 6.35$ days. Touré et al. [23] reported a similar mortality in a sample of 314 patients including patients admitted in intensive neurology care. Komolafe et al. [18] and Kouna et al. [17] estimated the mortality rate at $15.6 \%$ and $9.5 \%$ respectively. The difference between these mortality rates compared to that in the current study as well as that in Touré report is probably due to the fact that these studies did not include severe cases of patients hospitalized in intensive care unit. This hospital mortality rate is significantly lower in developed countries and is estimated to be around $13 \%$ to $14 \%$ [15] [16], and is relatively lower in developing countries around $19 \%$ [13].

\section{Conclusion}

The epidemiologic study of stroke in the Douala General Hospital suggests that cerebral haemorrhage and ischaemia have similar prevalence rates. The risk factors are similar to those described in the global literature. Hospital mortality is high and justifies that more action should be geared towards primary prevention in order to reduce the impact of stroke in our environment.

\section{References}

[1] Lopez, A.D., Mathers, C.D., Ezzah, M., Jamison, D.T. and Murray, C.J. (2006) Global and Regional Burden of Disease and Risk Factors. Systematic Analysis of Population Health Data. The Lancet, 367, 1747-1757. http://dx.doi.org/10.1016/S0140-6736(06)68770-9

[2] Volster, H.H. (2002) The Emergence of Cardiovascular Disease during Urbanization of Africans. Public Health Nutrition, 5, 239-243.

[3] Echouffo-Tcheugui, J.B. and Kengne, A.P. (2011) Chronic Non-Communicable Disease in Cameroun-Burden, Determinant and Current Policies. BMC Global Heath, 7, 44.

[4] Njamnshi, A.K., Mbong, E.N., Wonkam, A., et al. (2006) The Epidemiology of Stroke in Sickle Cell Patients in Yaounde, Cameroon. Journal of the Neurological Sciences, 250, 79-84. http://dx.doi.org/10.1016/j.jns.2006.07.003

[5] Njamnshi, A.K., Blackett, K.N., Mbuagbaw, J.N., Gamedze, F., Gupta, S. and Wiysonge, C.S. (2006) Chronic Chlamydiae Pneumoniae Infection and Stroke in Cameroon: A Case Control Study. Stroke, 37, 796-799. http://dx.doi.org/10.1161/01.STR.0000204223.04182.4a

[6] Obama, M.T., Dongmo, L., Nkemayim, C., Mbede, J. and Hagbe, P. (1994) Stroke in Children in Yaoundé, Cameroon. Indian Pediatrics, 31, 791-795.

[7] Mikande, Z., Ndoumba, A., Beyiha, G., et al. (2012) Stroke in the Hôpital Gynéco-Obstétrique et Pédiatrique de Yaoundé, epidemiology and paraclinical aspects. Schweizer archiv fur neurologie und psychiatrie, 163, 54-57.

[8] Beyiha, G., Minkande, E., Binam, F. and Sosso, M.A. (2008) Aspect épidémiologique et facteurs de gravité des AVC au Cameroun. Journal maghrébin d'anesthésie-réanimation et de médecine d'urgence, 15, 293-297.

[9] Chiasseu, M. and Mbahe, S. (2011) Descriptive Study of Cerebro-Vascular Accidents in Douala, Cameroon. Medecine Tropicale, 71, 492-494. 
[10] Mapoure, N.Y., Luma, N.H., Ngahane, H.B.M., et al. (2012) Prevalence of Stroke Risk Factors among Urban Population in Douala, Cameroon. Revue Médecine et de Pharmacie, 2, 143-144.

[11] Osuntokun, B.O., Bademosi, O., Akinkugbe, O.O., et al. (1979) Incidence of Stroke in a Africa City: Results from the Stroke Registry Ibadan, Nigeria, 1973-1975. Stroke, 10, 205-207. http://dx.doi.org/10.1161/01.STR.10.2.205

[12] Sagui, E., M’baye, P.S., Dubecq, C., et al. (2005) Ischemic and Hemorrhagic Strokes in Dakar, Senegal: A Hospital Based Study. Stroke, 36, 1844-1847. http://dx.doi.org/10.1161/01.STR.0000177864.08516.47

[13] Kumral, E., Ozkaya, B., Sagduyu, A., et al. (1998) The Ege Stroke Registry: A Hospital-Based Study in the Aegean Region, Izmir, Turkey. Analysis of 2.000 Stroke Patients. Cerebrovascular Diseases, 8, 278-288. http://dx.doi.org/10.1159/000015866

[14] Awada, A. and Al Rajeh, S. (1999) The Saudi Stroke Bank. Analysis of the First 1000 Cases. Acta Neurologica Scandinavica, 100, 265-269. http://dx.doi.org/10.1111/j.1600-0404.1999.tb00392.x

[15] Moulin, T., Tatu, L., Crépin-Leblond, T., et al. (1997) The Besançon Stroke Registry: An Acute Stroke Registry of 2.500 Consecutive Patients. European Neurology, 38, 10-20. http://dx.doi.org/10.1159/000112896

[16] Bornstein, N.M., Aronovich, B.D., Karepov, V.G., et al. (1996) The Tel Aviv Stroke Registry 3600 Consecutive Patients. Stroke, 27, 1770-1773.

[17] Kouna, N.P., Millogo, A., Siemefo, K.F., et al. (2007) Aspects épidémiologiques et évolutifs des accidents vasculaires cérébraux au centre hospitalier de Libreville (Gabon). African Journal of Neurological Sciences, 26, 122-130.

[18] Komolafe, M.A., Komolafe, E.O., Fatoye, F., et al. (2007) Profile of Stroke in Nigerians: A Prospective Clinical Study. African Journal of Neurological Sciences, 27, 360-365.

[19] Sagui, E. (2007) Les accidents vasculaires cérébraux vasculaires en Afrique subsaharienne. Medecine Tropicale, 67, 596-600.

[20] Feuzeu, L., Kengne, A., Balkau, B., et al. (2010) Ten-Year Change in Blood Pressure Levels and Prevalence of Hypertension in Urban and Rural Cameroon. Journal Epidemiology Community Health, 64, 360-365. http://dx.doi.org/10.1136/jech.2008.086355

[21] Amu, E., Ogunrin, O. and Danesi, M. (2005) Re-Appraisal of Risk Factors for Stroke in Nigerian Africans: Prospective Case-Control Study. African Journal of Neurological Sciences, 24, 78-83.

[22] Apetse, K., Matelbe, M., Assogba, K., et al. (2011) Prevalence of Dyslipidemia, Hyperglycemia and Hyperuricemia in Stroke Patients in Togo. African Journal of Neurological Sciences, 30, 88-93.

[23] Toure, K., Diagne, S.N., Seck, L.B., et al. (2010) Predictors of Stroke Mortality at the Department of Neurology, Fann University Teaching Hospital, Dakar-Senegal. Facteurs prédictifs de morbidité par AVC à la clinique neurologique du CHU de FANN, Dakar-Senegal. African Journal of Neurological Sciences, 29, 325-334.

[24] Napon, C., Sawadogo, R., Lampo, L., et al. (2011) Facteur de risque et étiologie de l'accident vasculaire cérébral ischémique du sujet jeune au Burkina Faso. Médecine d’Afrique noire, 58, 541-544. 
Scientific Research Publishing (SCIRP) is one of the largest Open Access journal publishers. It is currently publishing more than 200 open access, online, peer-reviewed journals covering a wide range of academic disciplines. SCIRP serves the worldwide academic communities and contributes to the progress and application of science with its publication.

Other selected journals from SCIRP are listed as below. Submit your manuscript to us via either submit@scirp.org or Online Submission Portal.
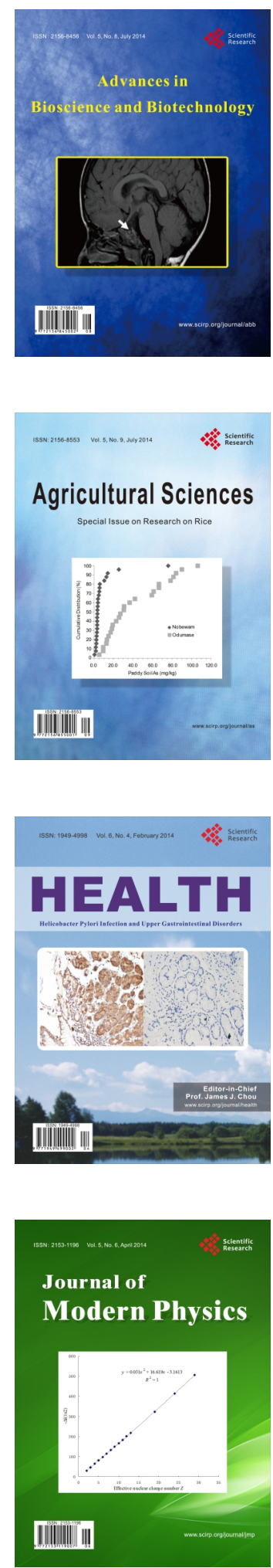
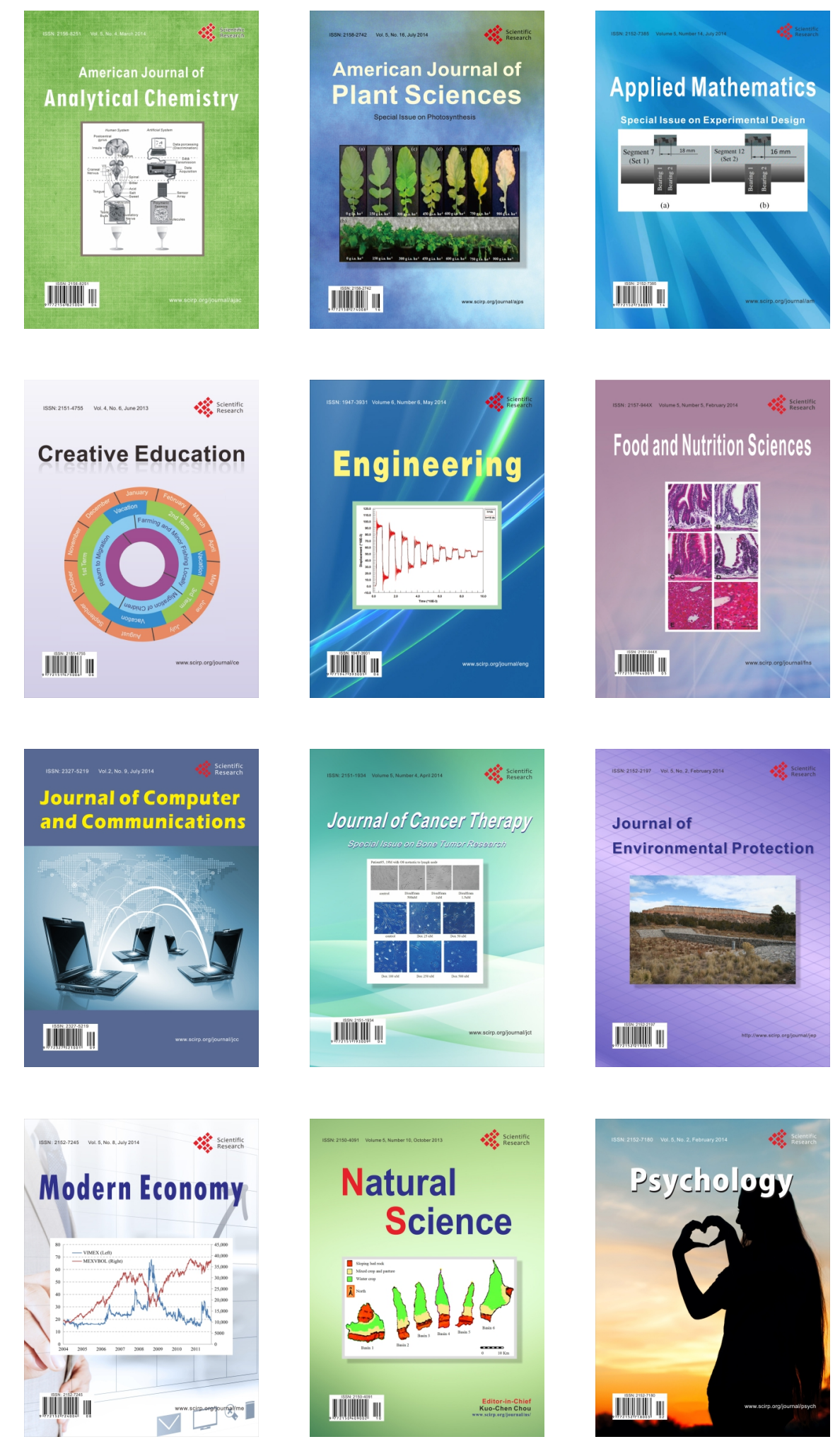